\title{
LA AUTORIDAD DEL DERECHO COMO CUESTIÓN DE JUSTICIA POLÍTICA
}

Marisa Iglesias Vila

En el trabajo que comentaré críticamente en estas páginas, Carlos Rosenkrantz reflexiona en torno a la fuerza normativa del Derecho y a la justificación de exigir obediencia a la autoridad jurídica incluso en situaciones de clara injusticia económica. Su rica aportación a esta problemática descansa, básicamente, en tres tesis centrales. En primer lugar, asume que una teoría de la autoridad del Derecho sólo podrá tener éxito si posee el grado suficiente tanto de generalidad como de particularidad. Así, por una parte, debe poder mostrar que el sistema jurídico genera obligaciones a todos aquellos a los que se aplica. Por otra parte, debe poder justificar obligaciones especiales, esto es, obligaciones que los que están sujetos a un ordenamiento tienen exclusivamente hacia su derecho.

En segundo lugar, Rosenkrantz defiende una teoría asociativa de la autoridad de lo jurídico como forma de satisfacer estos requisitos de generalidad y particularidad. Su propuesta consiste en conectar la obligación de obediencia al Derecho con la calidad de miembro de una comunidad política. Pero esta membresía sólo persistirá si no hay una situación de alienación como la que se origina cuando: a) las instituciones están organizadas para evitar que mis opiniones o mis intereses cuenten en la toma de decisión colectiva, o b) estas instituciones impiden, de hecho, que mis opiniones o mis intereses cuenten. Si no se dan estas condiciones de exclusión, la membresía en la comunidad política justificará la obligación de obediencia porque permite “el cambio sistémico", es decir, la posibilidad de actuar como colectivo que se auto-regula en contextos de fuerte pluralismo. 
Por último, una tercera tesis del profesor argentino es que el hecho de vivir en una situación de pobreza extrema no excluye a quien la padece del deber de obedecer su derecho siempre y cuando no se den estas condiciones para la alienación de la comunidad. Aquí los más pobres seguirán teniendo una razón moral, aunque sea prima facie, para hacer lo que el Derecho manda.

A pesar de que simpatizo con el marco teórico que se maneja en este trabajo y comparto la idea de que el Derecho tiene fuerza justificatoria, discrepo de la conclusión que Rosenkrantz obtiene. A mi juicio, una teoría razonable de la autoridad de lo jurídico no nos conduce a afirmar que las víctimas de la injusticia económica deben fidelidad al Derecho incluso en contextos donde las instituciones resultan incapaces de asegurar un mínimo bienestar para toda la población.

En este trabajo resaltaré algunas de las debilidades que creo que afectan a las tres tesis que defiende Rosenkrantz y trataré de mostrar cuáles son las razones por las que aceptar que el Derecho tiene fuerza normativa no nos compromete con la conclusión de este autor.

I

Acudir a los requisitos de generalidad y particularidad supone un paso importante en la comprensión de la autoridad específica que posee el Derecho. Por una parte, la vinculatoriedad moral de un instrumento que regula la convivencia social en el seno de la comunidad política debe poder abarcar a todos o a la mayoría de los miembros de la comunidad. Por otra parte, sin el elemento de particularidad cualquier teoría de la fuerza normativa del Derecho acabará cayendo en lo que C. S. Nino denominaba "paradoja de la superfluidad". Si la fuente de la obligación jurídica no permite distinguir, por

\footnotetext{
${ }^{1}$ En términos de Nino (1994, 131 y 58-59) la paradoja de la superfluidad daría cuenta del siguiente problema: "Si para que una norma jurídica justifique una acción o decisión debemos inevitablemente mostrar que emana de principios morales que se asumen como válidos ¿por qué no buscar la justificación de esa acción o decisión directamente en esos mismos principios? ¿Para qué necesitamos, al fin y al cabo, un gobierno y sus leyes si éstas no permiten justificar una acción más que recurriendo, en última instancia, a principios morales? Si las leyes coinciden con tales principios son redundantes, y si no coinciden no se les debe prestar atención".
} 
ejemplo, entre la obligación de obedecer el Derecho español y la de obedecer el Derecho francés, nuestros ordenamientos jurídicos serían moralmente superfluos. Esto es lo que sucedería, por ejemplo, si afirmáramos que es el carácter democrático de un conjunto de normas o su adecuación a ciertos principios de justicia universales lo que genera el deber de obediencia. En estos supuestos, siguiendo la posición de Rosenkrantz, la obligación jurídica iría más allá de la obligación de obedecer un sistema jurídico en particular porque abarcaría cualquier conjunto de normas con estas características y sólo sería predicable de un ordenamiento en concreto en la medida en que se ajustara a ellas. En este sentido, si, pongamos por caso, el ordenamiento francés fuera más democrático o más justo que el español, yo tendría una razón moral más fuerte para obedecer al primero que al segundo a pesar de ser ciudadana española.

Ahora bien, mi primera discrepancia con Rosenkrantz reside en su forma de entender qué es lo que exige el requisito de generalidad. Para este autor, una teoría exitosa de la autoridad del Derecho debe poder "dar cuenta de por qué todos aquellos a quienes el Derecho se aplica deben someterse a él” (p. 23). A partir de una analogía con la autoridad de los padres, afirma, "si nuestra explicación sólo diera cuenta de por qué algunos hijos deben obedecer a sus padres nunca sería una explicación de la autoridad de los padres. Alguien puede tener autoridad como padre únicamente si tiene autoridad sobre todos sus hijos" (p.18). En mi opinión, esta formulación de la generalidad es demasiado exigente porque presupone que la fuerza normativa de un ordenamiento jurídico sólo es predicable cuando todos sus destinatarios están bajo la misma fuente de obligación o cuando todos tienen un deber moral de obediencia. Desde esta perspectiva, mantener que los pobres no están plenamente vinculados por su Derecho tendría un costo teórico muy alto porque mostraría que no todos están obligados por su ordenamiento jurídico y, por tanto, que el Derecho carece de fuerza normativa.

Ciertamente, para que tenga sentido predicar que un ordenamiento jurídico tiene fuerza normativa debe poder vincular, de un modo u otro, a 
todos o a la mayoría de los miembros de la comunidad política. Ahora bien, la clase de los integrantes de la comunidad política no tiene por qué coincidir con la de los destinatarios de las normas. De hecho, la propia propuesta de Rosenkrantz en torno a quién cuenta como miembro de la comunidad política $y$, en consecuencia para él, está obligado por el derecho, excluye de la membresía al destinatario de las normas que podemos considerar alienado por el sistema jurídico. Si seguimos su propuesta, estamos asumiendo que no todos aquellos a los que el Derecho se aplica estarán necesariamente obligados por el Derecho. En definitiva, parece que si no flexibilizamos el requisito de generalidad, este criterio acaba haciendo inviable la propia posición de este autor en torno a este tema.

A mi juicio, la mejor forma de articular la exigencia de generalidad para valorar las teorías de la fuerza normativa del Derecho es acudir a la idea original de A. John Simmons, más flexible que la de Rosenkrantz. De acuerdo a Simmons, podríamos decir que el éxito de este tipo de teorías requiere "that an account be not only accurate and complete, but that it be reasonably general in its application, that is, that it entails that most (or at least many) citizens in most (or many) states are politically bound"2. En esta línea, lo que necesitamos para justificar la autoridad del Derecho es un grado razonable de generalidad que involucre a una parte muy significativa de los destinatarios de las normas. Este criterio más flexible nos permitirá no descartar a priori la compatibilidad entre afirmar que el derecho es autoritativo y rechazar que las víctimas de la injusticia social estén plenamente vinculadas por este derecho.

II

Cualquier teoría de la autoridad del Derecho requiere determinar qué características posee la relación jurídica para poder generar obligaciones especiales a los miembros de la comunidad política. Al mismo tiempo, debe

${ }^{2}$ Simmons (1979, 55 y 35-37). 
poder indicar qué rasgos, si es que es necesario alguno, debe poseer un ordenamiento para ser capaz de tener fuerza obligatoria en el marco de la relación jurídica. Siguiendo la línea dworkiniana, Rosenkrantz opta por una teoría asociativa de la autoridad del Derecho en la que es el vínculo político el que determina el contorno de la obligación de obediencia. A pesar de ello, se separa de Dworkin al considerar que la relación jurídica no requiere el elemento emotivo que encontramos en el modelo de la comunidad fraternal. Tampoco parece compartir el concepto normativo de Derecho de Dworkin centrado en el valor político de la integridad. Como es bien sabido, Dworkin considera que en la comunidad fraternal, donde sus integrantes tienen un interés específico e igualitario por el bienestar del resto de miembros, los participantes adquieren el compromiso de asociar el Derecho al equilibrio entre los valores que, en conjunto, justifican la coerción estatal (él sugiere para su ordenamiento tomar los valores de equidad, justicia y proceso debido). Desde esta perspectiva, las decisiones institucionales sólo constituirán derecho y, por tanto, serán autoritativas, en la medida en que, "hablando con una sola voz", implementen adecuadamente estos principios ${ }^{3}$.

Rosenkrantz está interesado en mostrar que el vínculo político, una vez que hemos excluido de su alcance las situaciones de alienación que he comentado en el apartado anterior, justifica que los miembros de una comunidad difieran su juicio a las normas que dicha comunidad ha diseñado para regular la convivencia (p. 48). Este vínculo tiene valor justificatorio porque, en última instancia, permite a un grupo de personas actuar como una comunidad, como uno sólo en contextos de pluralismo irreducible. Pero la pregunta que cabría efectuar es si la propuesta de Rosenkrantz puede erigirse en una teoría exitosa de la autoridad del Derecho desde los propios parámetros que utiliza este autor.

La primera dificultad que enfrenta esta perspectiva es la indefinición del vínculo político. Si el único elemento que tomamos para calibrar qué es lo que me hace miembro de una comunidad política es que las instituciones no

${ }^{3}$ Véase Dworkin (1986, caps. 6 y 7). 
impidan por activa o por pasiva que mis intereses u opiniones cuenten en la toma de decisión pública, parece que cualquiera que no sea excluido pasará automáticamente a ser miembro de la comunidad. Esta idea es demasiado abarcativa para cumplir con el requisito de particularidad que necesitamos para justificar la autoridad especial del Derecho. De hecho, en la toma de decisión pública pueden contar opiniones o intereses muy diversos, incluso de personas o entidades que no forman parte de la comunidad. Esto sucede, por ejemplo, cuando en un mundo globalizado las decisiones públicas tienen efectos que van mucho más allá de las fronteras nacionales o cuando, en la práctica, las instituciones de una comunidad tienen en cuenta intereses económicos o políticos externos. Por esta razón, resulta más razonable afirmar que es, precisamente, mi condición de miembro de una comunidad política o, en otros términos, el vínculo político que mantengo con otros, lo que hace exigible que mis opiniones o intereses no sean excluidos. Si la alienación se produce, ciertamente habré dejado de ser tratada como miembro de la comunidad. Ahora bien, ello no implica que la ausencia de alienación sea la relación que define la membresía; lo que hace es establecer un límite normativo. Por esta razón, Rosenkrantz acaba observando que las situaciones de alienación muestran que "carezco del vínculo adecuado con mi comunidad” (p.43). Pero ¿cuál es el vínculo que me permite afirmar que ésta es $m i$ comunidad?

La cuestión que queda sin responder, entonces, es qué es lo que caracteriza al vínculo político, un vínculo tan importante que permite justificar que excluyamos a los que no son miembros (y sólo a los que no son miembros) de cualquier influencia en las decisiones públicas. Una vez descartados los lazos afectivos, Rosenkrantz observa que "el criterio de membresía no puede consistir en una exigencia directa e incondicionada de requisitos procedimentales y sustantivos" (p. 43). Tampoco resulta suficiente, a los efectos de justificar un deber de obediencia, tomar como criterio el mero hecho de haber nacido en un determinado territorio. Un hecho, por si mismo, carece de valor justificatorio. Este autor también descarta el argumento del 
consentimiento, ya sea expreso o tácito, y las teorías del fair play, que podrían ser entendidas como una propuesta de asociar el vínculo político a una relación de beneficio mutuo.

En última instancia, Rosenkrantz parece hace descansar el carácter especial del vínculo jurídico-político en el valor del cambio sistémico o, en otras palabras, en el valor de la preservación de la comunidad. Estamos involucrados en la relación jurídica cuando tenemos "un sistema de toma de decisiones que todos pueden aceptar (un sistema en el que todos de hecho participan o cuentan al momento de tomar decisiones y nadie está de derecho impedido de participar o contar)" (p. 48). Siguiendo de nuevo sus palabras, "el derecho nos ofrece esta posibilidad, y es por ello que sirve un valor que todos, en tanto nos interese permanecer vinculados como comunidad, debemos apreciar"' (p. 49).

Esta idea es algo oscura y necesitaría un mayor desarrollo para poder contar como un modo de caracterizar el tipo de vínculo que genera obligaciones a los miembros individuales de una comunidad. A mi juicio, no queda claro en su exposición qué es lo que permite afirmar que la ausencia de alienación hace posible hablar de los actos de una comunidad como algo diferente a un cúmulo de actos individuales. Podríamos indicar que cuando no hay alienación las decisiones de mi comunidad cuentan como decisiones autónomamente adoptadas por mi, esto es, como decisiones autoimpuestas. Pero Rosenkrantz rechaza esta línea de argumentación (p. 44). También podríamos afirmar que la ausencia de alienación refuerza nuestra identificación con una comunidad y con los actos que se realizan en su nombre. Aquí sería el valor que otorgamos a nuestra identidad social lo que generaría obligaciones especiales hacia esa comunidad. Pero esta clase de argumentos nos acercan o bien a los enfoques comunitaristas o bien a la perspectiva del Derecho como integridad de Dworkin y su modelo de comunidad fraternal. Rosenkrantz también descarta acertadamente esta alternativa porque, entre otras cosas, no puede dar cuenta del tipo de lazos que conforman la asociación política en comunidades grandes y anónimas como las que vivimos (pp. 37-40 y 49). 
¿Qué nos queda para caracterizar la relación jurídica como relación especial que genera un deber de obediencia? Si aceptáramos la tesis de Simmons -y de muchos otros- en realidad no nos quedaría nada ${ }^{4}$. La conclusión debería ser, entonces, que no podemos justificar obligaciones de obediencia al Derecho porque no podemos justificar la presencia de un vínculo político con fuerza justificatoria que cumpla los requisitos de particularidad y generalidad.

No es nada fácil evitar la conclusión de Simmons, ya que quizá sea cierto que cualquier alternativa tendrá algún déficit en relación con estos requisitos. A pesar de ello, creo que la línea de trabajo de Dworkin sigue siendo la más razonable para dar cuenta de la autoridad de lo jurídico si conseguimos desvincularla de cualquier exigencia de lazos emotivos. Me detendré de nuevo en algunas de las objeciones de Rosenkrantz a esta teoría asociativa antes de explicar por qué creo que puede ser una alternativa razonable.

La primera objeción que comentaré es la de que el Derecho no puede ser vinculante solamente si nos encontramos en una comunidad fraternal donde sus miembros se comprometen con la igual consideración y respeto para todos (p. 38). En opinión de Rosenkrantz, el Derecho debe poder obligar incluso en sociedades donde sus miembros tienen una preocupación desigual por los otros y por su bienestar. Para ilustrar esta idea pone como ejemplo una comunidad política dividida donde conviven dos grupos religiosos muy diferentes y con recelo recíproco. En este caso, los miembros de cada grupo religioso circunscribirán su interés igualitario a los miembros de su propio grupo. Desde la perspectiva de Dworkin, indica Rosenkrantz, en esta comunidad política dividida no se darían las condiciones de igual consideración y respeto para poder afirmar que sus miembros tienen la obligación especial de obedecer el Derecho que se aplica al conjunto de su comunidad política.

Aunque pueda ser cierto que la comunidad idealizada de Dworkin no se corresponde con las comunidades políticas reales en las que nos preguntamos

\footnotetext{
${ }^{4}$ Véase, por ejemplo, Simmons (1979, 191-201), Green (2002).
} 
por la vinculación al Derecho de los más pobres, creo que esta crítica de Rosenkrantz no es justa con la posición de Dworkin. En el ejemplo que plantea lo que tendríamos en realidad serían dos comunidades políticas. El derecho como integridad regiría dentro de cada una ellas, pero no entre ellas $^{5}$. Cabe tener en cuenta, como insistiré más adelante, que la comunidad fraternal de Dworkin compromete a sus instituciones con valores que no tienen un alcance universal. La integridad se extiende hasta donde se extiende la fraternidad y la preocupación igualitaria por otros que conforman una comunidad. Podemos discrepar de esta propuesta y, también, rechazar que un ordenamiento jurídico, para ser tal y tener fuerza vinculante, requiera un compromiso con la integridad. Pero ésta ya es una cuestión diferente que está relacionada con el mínimo procedimental y sustantivo que requerimos de un conjunto de decisiones de autoridad para que pueda transformar coerción en Derecho. En mi opinión, el criterio de ausencia de alienación no es suficiente para este fin 6 .

La segunda objeción del profesor argentino se refiere a la concepción dworkiniana de la asociación política en la comunidad fraternal. Como observé anteriormente, Dworkin acaba tratando este vínculo de forma análoga a la relación familiar y de amistad. Rosenkrantz rechaza esta analogía por dos razones. Por una parte, el vínculo político no está necesariamente basado en sentimientos. Por otra parte, este vínculo, a diferencia de la relación familiar, no va de miembro a miembro y, por tanto, no es individual sino colectivo, "no se da uno a uno sino, digamos, uno a todos" (p. 47), ya que este vínculo lo que en parte persigue es "la construcción de una comunidad" (p. 41).

\footnotetext{
${ }^{5}$ Esta situación sería análoga a la que Dworkin (1986, 185-186) presenta cuando se refiere al alcance de la integridad en un estado federal. Aquí insiste en que las exigencias y la fuerza de la integridad no abarcan a toda la federación sino que estarían limitadas a cada estado o comunidad dentro del estado federal.

${ }^{6}$ No entraré a valorar si el concepto de alienación que maneja Rosenkrantz es adecuado. Sobre esta cuestión, véase, por ejemplo, Gaido (2005). Otra visión diferente en torno a cuándo estamos ante una situación de alienación jurídica puede encontrarse en Gargarella (2003).
} 
Esta objeción me parece claramente acertada. Este punto débil de la propuesta dwokiniana le impide satisfacer tanto el requisito de generalidad (ya que muchos de los destinatarios del derecho carecen de la actitud fraternal hacia sus conciudadanos) como el de particularidad (ya que no consigue dar una explicación convincente del carácter especial de la relación jurídica). Pero ello no implica que el Derecho como integridad deba ser descartado como teoría de la autoridad de lo jurídico. Lo único que implica es que debemos desvincular el compromiso con la integridad de los lazos emotivos dentro de una comunidad fraternal.

Como he comentado, la teoría asociativa que sugiere Rosenkrantz está demasiado desdibujada como para constituir una alternativa al Derecho como integridad. Una comunidad donde nuestros vínculos dependen únicamente de la ausencia de alienación y sólo tienen como valor la posibilidad del cambio sistémico nos dice poco de por qué debemos obedecer el Derecho de nuestra comunidad. Si su pretensión al abogar por la autoridad del Derecho es, en definitiva, tratar de asegurar que no estaremos en la situación en "la que cada uno actúa de acuerdo con sus propios juicios de justicia” (nota 55), lo que necesitamos es, precisamente, lo que proyecta el Derecho como integridad, esto es, fusionar “citizens' moral and political lives: it asks the good citizen, deciding how to treat his neighbor when their interest conflict, to interpret the common scheme of justice to which they are both committed just in virtue of citizenship"?.

Rosenkrantz asume que la única forma de seguir actuando como comunidad en contextos donde, pongamos por caso, las personas tienen diferentes concepciones de la igualdad "es encontrar algún mecanismo que les permita cambiar como comunidad, sistémicamente, en el caso del ejemplo, eligiendo una sola concepción de la igualdad para honrar" (p. 48). Pero esta idea nos conduce a una aproximación mucho más exigente y sustantiva en

${ }^{7}$ Dworkin (1986, 189-190). 
torno al Derecho que la que deriva de la mera ausencia de alienación. Para construir una comunidad en este sentido no sólo requerimos que no se nos impida participar, sino comprometernos activamente con unos principios comunes de justicia y sentirnos responsables de su implementación ${ }^{8}$. En suma, la idea de Rosenkrantz de actuar como comunidad es paralela a la de Dworkin de hablar con una sola voz; y, en mi opinión, para tener la misma fuerza justificatoria que la de Dworkin necesita una visión más sustantiva del vínculo político y de qué es el Derecho en general.

Mi sugerencia es que esta visión más sustantiva requiere defender el modelo del Derecho como integridad sin acudir a una asociación basada en vínculos emotivos para poder justificar la autoridad especial del Derecho. Como explicaré a continuación, creo que para cumplir el requisito de particularidad sólo necesitamos conectar la integridad con el valor de la equidad social en tanto exigencia de justicia política (entendiendo que la justicia política constituye una dimensión específica de la moralidad que gobierna los arreglos sociales en el marco de un esquema de cooperación social donde se asume la posibilidad de ejercer la coerción ${ }^{9}$ ).

III

Un primer paso para justificar por qué el Derecho como integridad satisface el requisito de particularidad es insistir en el carácter político del valor de la integridad y en la conexión entre el Derecho y la coerción. Para Dworkin, el Derecho no es meramente un modo de organizar la coerción

\footnotetext{
${ }^{8}$ Véase Dworkin $(1986,190)$.

${ }^{9}$ Véase, en este sentido, por ejemplo, Rawls (1993, 11-22), Nagel (2005). Podríamos afirmar que necesitamos acudir a la justicia política, precisamente, en aquellos contextos de relación social donde, por una parte, ya no podemos justificar obligaciones especiales derivadas de nuestros lazos afectivos con allegados y amigos y, por otra parte, pretendemos generar un rango de obligaciones más amplio que el que deriva de la relación moral universal por excelencia que exige no dañar a otros y de aquello que nos debamos los seres humanos entre nosotros.
} 
estatal sino un modo de justificar esa coerción que pueden ejercer las instituciones para regular la convivencia dentro de una comunidad política ${ }^{10}$. Su propuesta es que el respeto al ideal de integridad constituye la manera específica de justificar en este contexto la posibilidad de ejercer la fuerza. De ahí que el compromiso con la integridad esté circunscrito. En tanto valor político, la fuerza justificatoria de la integridad tiene un alcance local que puede entrar en conflicto con principios generales de justicia. En este sentido, satisfaría el requisito de particularidad porque, como observa Dworkin, "can claim authority of a genuine associative community and can therefore claim moral legitimacy -that its collective decisions are matters of obligation and not bare power- in the name of fraternity. These claims may be defeated, for even genuine associative obligations may conflict with, and must sometimes yield to, demands of justice"11.

Ahora bien, aunque el Derecho como integridad sólo podrá actuar en el seno de una comunidad de principio, esto es, una comunidad donde sus participantes adquieren el compromiso de gobernarse por unos principios comunes que justifiquen la coerción del estado, no requiere tanto como una comunidad fraternal. Esta comunidad de principio puede verse como una simple exigencia de equidad social, entendida como la aspiración de crear una base razonable para la cooperación social dentro de un grupo humano donde sus miembros merecen la misma consideración y respeto ${ }^{12}$. La conexión

${ }^{10}$ Véase Dworkin (1986, 90-101).

${ }^{11}$ Dworkin $(1986,214)$.

${ }^{12}$ Cabe advertir que Dworkin, cuando habla de los tres valores justificatorios, utiliza la palabra "equidad" para hacer referencia a la igualdad de participación o influencia política. Éste es un sentido diferente de "equidad" que el propio Dworkin distingue del que manejaré aquí. La idea de equidad social es mucho más genérica que el principio de fair play, que tantas críticas ha recibido como forma general de justificar la obligación política. Sobre estas críticas, véase, por ejemplo, el conocido estudio de Simmons (1979, cap. 5). Aunque no estoy aquí en disposición de poder examinar esta distinción, podríamos apuntar que el principio de fair play está directamente supeditado a la idea de beneficio mutuo. La equidad social, en cambio, estaría asociada, entre otras cosas, a un concepto más general como es el de reciprocidad. En otra ocasión estudiaré con detenimiento las implicaciones morales de aceptar un compromiso con la 
que la integridad pueda tener con la equidad social es mucho más básica que la que deriva de la idea de comunidad fraternal, pero sigue moviéndose dentro del ámbito de la justicia política. A mi modo de ver, esta conexión surge cuando nos preocupamos por el control de la coerción dentro de una comunidad humana.

Con independencia de que podamos preguntarnos si el proyecto colectivo circunscrito que supone una unidad política está justificado desde parámetros universales de justicia o de que podamos cuestionar la legitimidad de las fronteras políticas, lo cierto es que estas unidades políticas existen y que no podemos prescindir de ellas. También es cierto que en el seno de estas unidades sus miembros pueden ejercer y recibir recíprocamente coerción a través de una estructura institucional ${ }^{13}$. Este elemento contextual genera una relación moral especial, un marco que reclama cooperación equitativa, y es la justicia política la que se preocupa por cómo puede justificarse esta posibilidad de coerción recíproca ${ }^{14}$. Nagel ha expresado esta idea con mucha claridad. En sus palabras, "every state has the boundaries and population it has for all sorts of accidental and historical reasons; but given that it exercises sovereign power over its citizens and in their name, those citizens have a duty of justice toward one another through the legal, social, and economic institutions that sovereign power makes possible"15.

reciprocidad. Valga indicar ahora, siguiendo las consideraciones de Rawls (1993, 16-17) en Political Liberalism, que la reciprocidad estaría a medio camino entre el ideal de imparcialidad, que es altruista, y la exigencia de ventaja mutua. En este sentido, la reciprocidad no exigiría meramente conformar una comunidad de beneficio mutuo sino una comunidad de principio gobernada por estándares generales, comunes y razonables de justicia.

${ }^{13}$ Ya observaba Hart (1961) que, dada nuestra relativa igualdad física, nadie puede concentrar todo el monopolio de la coerción sin cooperación.

${ }^{14}$ Incluso podríamos afirmar, siguiendo a Nagel $(2005,145)$, que es de hecho usual que la concentración de poder preceda a las demandas de legitimidad. En sus términos, "first there is the concentration of power; then, gradually, there grows a demand for consideration of the interests of the governed, and for giving them a greater voice in the exercise of power. (...) it is the existence of concentrated sovereign power that prompts the demand, and makes legitimacy an issue".

${ }^{15}$ Nagel $(2005,120-121)$. 
Desde esta perspectiva, lo que nos hace miembros de una comunidad política y no meros sujetos activos o pasivos de una estructura coercitiva es la sujeción, en tanto personas con igualdad moral, a una exigencia mutua de equidad en el diseño de nuestros arreglos sociales. Esta sujeción y, por tanto, la membresía, empieza desde el momento en que formamos parte, lo hayamos elegido o no, de estas estructuras que canalizan la vida social y donde es posible ejercer la fuerza. El derecho, por su parte, es el instrumento que utilizamos para asegurar que estos arreglos sociales se llevarán a cabo de forma equitativa. En el modelo normativo de Dworkin, es el respeto a la integridad lo que permitirá transformar el mero ejercicio de fuerza en Derecho. La virtud de la integridad podrá jugar este papel transformador sólo si, por una parte, permite asegurar que esta coerción es ejercida en nombre de todos $y$, por otra parte, posibilita arreglos sociales que cumplan los mínimos procedimentales y sustantivos que una relación equitativa exige en una sociedad de iguales donde interviene la coerción ${ }^{16}$. En este sentido, la exigibilidad de un compromiso con la integridad no requiere tanto como la presencia de una comunidad fraternal. Pero sí requiere la presencia de un contexto donde puedan entrar en juego lo que suelen denominarse "estándares comparativos de justicia", que justifican derechos y expectativas individuales a partir de comparar la situación de ventaja o desventaja social de unos individuos respecto a otros ${ }^{17}$. La comunidad política, en tanto marco

\footnotetext{
${ }^{16}$ En sentido parecido, Rawls (1993, 136-138, 214) concibe su propuesta de un liberalismo político como la forma adecuada de justificar el ejercicio de la coerción en sociedades en las que la pertenencia no es generalmente algo voluntario y donde sus miembros poseen diferentes concepciones de lo bueno.

${ }^{17}$ Siguiendo, por ejemplo, a Miller (1999, 4-5, 19, 220-221; 1998, 171, 180), cabría indicar que los principios no comparativos, en cambio, justifican derechos y expectativas individuales sin tener en cuenta la relativa situación de otras personas y sus derechos. En opinión de Miller $(1998,171)$, mientras que los principios no comparativos pueden tener un alcance global, los de carácter comparativo requieren "persons who are connected together in some way, for instance by belonging to the same community".
} 
institucional que canaliza relaciones recíprocas de poder, constituye uno de estos contextos.

En definitiva, creo que es posible dar cuenta de la autoridad del Derecho desde los parámetros de esta visión asociativa porque se satisfacen de modo razonable los requisitos de generalidad y particularidad. Ahora bien, desde esta perspectiva, ser miembro de la comunidad política no implica, como sí parece presuponer Rosenkrantz, un mero deber de obedecer las reglas que dictan las autoridades normativas. Como observa acertadamente Dworkin, "political obligation is then not just a matter of obeying the discrete political decisions of the community one by one. (...) It becomes a more protestant idea: fidelity to a scheme of principles each citizen has a responsibility to identify, ultimately for himself, as his community's scheme"18. Esta reflexión es importante para valorar hasta qué punto las víctimas de la injusticia económica están vinculadas por las reglas que dictan las autoridades normativas cuando los arreglos sociales de su comunidad resultan ineficaces para garantizar un mínimo bienestar a todos. ¿Requiere el Derecho garantizar un mínimo redistributivo para mantener una fuerza vinculante plena? A mi juicio, contrariamente a lo que opina Rosenkrantz, debemos dar una respuesta afirmativa a esta cuestión desde el momento en que pretendemos defender con éxito que el Derecho es autoritativo.

\section{IV}

En el apartado anterior he comentado que la única alternativa que, en mi opinión, puede fundamentar de modo razonable la fuerza normativa de lo jurídico es la perspectiva del Derecho como integridad asociada a los parámetros de equidad social. Desde este punto de vista, el Derecho justifica la coerción en tanto instrumento de una comunidad política para diseñar

\footnotetext{
${ }^{18}$ Dworkin $(1986,190)$.
} 
arreglos sociales que son fruto de la cooperación equitativa entre personas que gozan de igualdad moral. Mi sugerencia ha sido entender que esta cooperación equitativa es exigible desde el momento en que nos hallamos en un contexto de interacción colectiva donde es posible el ejercicio recíproco de la fuerza entre iguales.

Ello no impide reconocer que los arreglos sociales de cada comunidad política pueden ser diferentes, del mismo modo que pueden serlo los estándares de equidad que les gobiernan. Ello tampoco impide reconocer que, satisfaciendo las mismas exigencias de cooperación equitativa, habrá comunidades políticas que tendrán más éxito que otras en relación al nivel de bienestar que sus integrantes obtienen fruto de la dinámica de su proyecto colectivo. Por esta razón, debemos ser cautelosos con aquello que exigimos de un sistema jurídico para tener fuerza vinculante.

A mi modo de ver, el aspecto sustantivo que un ordenamiento debería satisfacer como instrumento de equidad social para poder transformar coerción en Derecho se reduce a una exigencia de mínimos. En este punto puede ser útil acudir a la distinción de Rawls entre dos tipos de cuestiones complementarias de justicia política que conforman un sistema de razón pública: las cuestiones de mínimos constitucionales y las de justicia básica ${ }^{19}$. Las primeras involucran principios relativos a nuestras libertades básicas. Las segundas involucran estándares de igualdad económica y social. El primer tipo de cuestiones, por una parte, tienen la función particular de controlar "how political power is acquired and the limits of its exercise" y, por otra parte, requieren un acuerdo urgente para poder configurar las bases de una comunidad política equitativa $^{20}$. El segundo tipo de cuestiones, en cambio, no posee un carácter tan urgente ni el acuerdo sobre ellas será tan fácil. Al mismo tiempo, tienen una función diferente, la de implementar institucionalmente el ideal de una sociedad entre personas libres e iguales.

\footnotetext{
${ }^{19}$ Véase Rawls (1993, 227-230).

${ }^{20}$ Rawls $(1993,229)$.
} 
Podríamos afirmar que el Derecho, en su carácter de instrumento de una comunidad política que está asociado directamente al ejercicio del poder coercitivo, tiene su límite sustantivo en los mínimos constitucionales y no en las cuestiones de justicia básica. Ahora bien, como también observa acertadamente Rawls, aunque sea cierto que la igualdad económica en la forma de un principio de diferencia no entra dentro de los mínimos constitucionales, sí formaría parte de este mínimo constitucional la garantía de un "social minimum providing for the basic needs of all citizens" ${ }^{21}$. En este sentido, creo que es razonable afirmar que cuando un ordenamiento resulta ineficaz para proveer de un mínimo social que garantice la supervivencia de todos los miembros de la comunidad política, las víctimas de la pobreza no pueden estar plenamente vinculadas por su derecho. De este modo, discrepo de la posición de Rosenkrantz cuando observa que el deber de obediencia de los pobres sólo desaparecerá cuando el sistema sea un instrumento para la perpetuación de la injusticia económica y no, meramente, cuando carezca de eficacia para resolver la injusticia social. En opinión de este autor, el deber se mantiene cuando los intereses y las opiniones han sido considerados en la toma de decisión pública (pp. 51). El criterio de Rosenkrantz es insuficiente porque, como observa Paula Gaido, no tiene en cuenta cómo los intereses han sido realmente actualizados ${ }^{22}$. Así, aunque Rosenkrantz tenga razón al afirmar que la legitimidad del sistema político que usa el instrumento jurídico "no está condicionada a la realización de la justicia distributiva" (p. 52), tampoco se puede independizar completamente de la distribución.

Ello no implica, claro está, que un ordenamiento jurídico ineficaz para garantizar un mínimo social deje de tener fuerza obligatoria con respecto a aquellos cuya subsistencia no está en peligro (siempre que se satisfagan otros

\footnotetext{
${ }^{21}$ Rawls (1993, 228-229).

${ }^{22}$ Véase, en este sentido, Gaido $(2005,7)$. Afirmar, como hace Rosenkrantz, que Argentina no es un país que se olvida de sus pobres porque su situación ha sido tenida en cuenta en el diseño de arreglos sociales no es suficiente para legitimar el sistema argentino. En este caso, la legitimidad requiere cierto grado de eficacia redistributiva.
} 
mínimos constitucionales) ${ }^{23}$. Sería paradójico que en estos casos acabáramos concluyendo que aquellos que han sido beneficiados por la estructura distributiva también quedan liberados de la obligación de obedecer. Ello tampoco implica afirmar que las víctimas de la injusticia económica dejen de estar vinculadas por cualquier norma de este sistema ineficaz. Desde la lógica de la equidad, lo que perdería fuerza vinculante para los pobres serían lo que podríamos denominar "normas cooperativas", esto es, normas que distribuyen las cargas para la obtención de bienes colectivos. Aunque desconozco en toda su extensión el caso argentino y el problema de los piqueteros, cabría afirmar que las normas que protegen de la invasión de la vía pública sin autorización pertenecen a esta categoría ${ }^{24}$.

Obviamente, hay normas mucho más básicas, como las que prohíben, pongamos por caso, el homicidio, las agresiones o el robo, cuya vinculatoriedad general puede incluso independizarse de las exigencias de equidad social y de las fuentes de obligaciones especiales ${ }^{25}$. Para justificar un deber de obedecer estas normas más básicas podemos acudir con éxito a estrategias diversas como, por ejemplo, a la relación moral universal de no dañar a otros. Ahora bien, en estos casos, como advierte Simmons, nuestras razones para obedecer estas normas en nuestro ordenamiento serán las mismas que tendríamos para respetar esas normas en un ordenamiento extranjero ${ }^{26}$.

${ }^{23}$ En mi opinión, sería muy reduccionista suponer que, si el Derecho obliga, debe hacerlo en toda la extensión de sus normas y respecto a todos sus destinatarios.

${ }^{24}$ Esto no supone que cualquier fallo en el esquema redistributivo libere a las víctimas de la injusticia de su "deber de civilidad", en terminología rawlsiana. Este deber, siguiendo a Rawls $(1971,355)$, prohíbe invocar "the faults of social arrangements as a too ready excuse for not complying with them, nor to exploit inevitable loopholes in the rules to advance our interests. The duty of civility imposes a due acceptance of the defects of institutions and a certain restraint in taking advantage of them". Así, sólo en los casos extremos en los que el sistema político es claramente ineficaz para garantizar la supervivencia pueden llegar a cancelarse las obligaciones hacia el Derecho de aquellos que sufren una pobreza extrema.

${ }^{25}$ Véase, en sentido análogo, la posición de Rawls $(1999,118)$ sobre por qué el deber de obedecer las leyes que prohíben la violencia criminal no requiere acudir al fundamento del fair play social. Sobre este punto véase, también, Simmons (1979, 194), Rawls (1971, 114-116).

${ }^{26}$ Simmons $(1979,194)$. 
Desde mi punto de vista, en definitiva, sería erróneo afirmar, como pretende Rosenkrantz, que las víctimas de la injusticia económica siguen teniendo un deber especial prima facie de obedecer su Derecho ${ }^{27}$. No se trata meramente de que estas personas puedan estar sujetas a otros deberes morales con más peso en una situación particular o que en los casos más extremos deje de estar justificado o bien el reproche o bien el castigo. Mi tesis es que el Derecho no puede vincularles plenamente si no es capaz de garantizar su supervivencia ${ }^{28}$. Claro que siempre podremos afirmar que, con independencia de estar sujetos a un deber moral de obediencia, los pobres deberían atender a aquellas razones prudenciales que aconsejan respetar los mandatos de su Derecho. Rosenkrantz apela también a este argumento al final de su trabajo. Pero creo que deberíamos centrarnos aquí en las razones morales porque, al fin y al cabo, las razones prudenciales sólo adquieren sentido para aquellos que tienen algo que perder.

\footnotetext{
${ }^{27}$ Algo diferente sería predicar que, como destinatarios de las normas, los pobres tienen, prima facie, un deber de obediencia. Cuando tenemos un deber prima facie, estamos ante un deber que puede ser vencido por otro en caso de conflicto entre ambos. Pero a pesar de haber sido vencido en una situación particular seguiremos teniendo ese deber. En cambio, cuando afirmamos que tenemos prima facie un deber estamos asumiendo que, desde una aproximación superficial o genérica parece que poseemos este deber. Un análisis cuidadoso puede acabar mostrando que realmente este deber no existe. Sobre esta distinción, véase, por ejemplo, Jones (1994, 195-198).

${ }^{28}$ Sobre la cuestión de qué cartas pueden jugar las víctimas de la injusticia social y económica para resistir una situación institucional injusta, véase la aportación de Gargarella (2003).
} 


\section{BIBLIOGRAFÍA}

Dworkin, Ronald (1986), Law's Empire, Fontana Press, Londres.

Gaido, Paula (2005), "Do the Poor Have the Duty to Obey the Law?", en Ferrer, J., y Pozzolo, S. (edts.), Ethics and Social Justice, Duncker \& Humblot, Berlín (en prensa).

Gargarella, Roberto (2003), "La última carta. El derecho de resistencia en situaciones de alienación legal”, en R. Saba (ed.), Violencia y Derecho, Editores del Puerto, Buenos Aires, 295-319.

Green, Leslie (2002), "Law and Obligations", Coleman, J. y S. Shapiro (ed.), The Oxford Handbook of Jurisprudence \& Philosophy of Law, Oxford University Press, 514-547.

Hart, Herbert L.A. (1961), The Concept of Law, Oxford University Press. Jones, Peter (1994), Rights, Macmillan, Londres.

Miller, David (1998), "The limits of Cosmopolitan Justice”, en Mapel, D. y Nardin, T. (eds.), International Society: Diverse Ethical Perspectives, Princeton University Press.

Miller, David (1999), Principles of Social Justice, Harvard University Press, Cambridge (Massachusetts).

Nagel, Thomas (2005), "The Problem of Global Justice", Philosophy \& Public Affairs, 33, n. 2, 113-147.

Nino, Carlos Santiago (1994), Derecho, moral y política, Ariel, Barcelona.

Rawls, John (1971), A Theory of Justice, The Belknap Press of Harvard University Press, Cambridge (Massachusetts).

Rawls, John (1993), Political Liberalism, Columbia University Press, New York.

Rawls, John (1999), "Legal Obligation and the Duty of Fair Play", en Freeman. S. (ed.), John Rawls: Collected Papers, Harvard University Press, Cambridge, (Massachusetts), 117-129.

Simmons, A. John (1979), Moral Principles and Political Obligations, Princeton University Press. 